\title{
QBO effects on the diurnal tide in the upper atmosphere
}

\author{
M. E. Hagan ${ }^{1}$, M. D. Burrage ${ }^{2}$, J. M. Forbes ${ }^{3}$, J. Hackney ${ }^{1}$, W. J. Randel ${ }^{1}$, and X. Zhang ${ }^{3}$ \\ ${ }^{1}$ National Center for Atmospheric Research, Boulder, Colorado, U.S.A. \\ ${ }^{2}$ Space Physics Research Laboratory, University of Michigan, Ann Arbor, U.S.A. \\ ${ }^{3}$ Department of Aerospace Engineering Sciences, University of Colorado, Boulder, U.S.A. \\ (Received August 20, 1998; Revised January 25, 1999; Accepted January 25, 1999)
}

\begin{abstract}
We report on a series of numerical experiments conducted with the global-scale wave model (GSWM) and designed to investigate the effects of the quasi-biennial oscillation $(\mathrm{QBO})$ on the migrating diurnal tide. Our results indicate that the diurnal tidal response in the upper mesosphere and lower thermosphere (MLT) is significantly affected by the QBO in zonal mean zonal winds, but largely insensitive to the QBO in stratospheric ozone. We discuss the variable mean wind results in light of previous analytic attempts to describe the diurnal tide in the presence of mean winds and dissipation. Our calculations do not explain the interannual tidal variations observed by the High Resolution Doppler Interferometer (HRDI) on the Upper Atmosphere Research Satellite (UARS).
\end{abstract}

\section{Introduction}

Many years ago Lindzen (1972) and Lindzen and Hong (1974) described some of the important effects of zonal mean zonal winds and horizontal temperature gradients on atmospheric tides. Since that time monthly climatologies of zonal mean winds and temperatures based on empirical or semiempirical models (Batten, 1961; Kantor and Cole, 1964; Murgatroyd, 1965; Murphy, 1969; CIRA (1972); U.S. Standard Atmosphere (1976)) have been routinely employed in linear tidal models (Walterscheid et al., 1980; Aso et al., 1981; Forbes, 1982; Vial, 1986; Forbes and Hagan, 1988; Forbes and Vial, 1989) to account for these effects. Hagan et al. (1995) used a series of background wind models (Groves, 1985, 1987; Portnyagin and Solov'eva, 1992a,b) and the socalled MSISE-90 temperature model (Hedin, 1991) in the initial formulation of the linear tidal and planetary wave model known as GSWM. Recently, Hagan et al. (1999) updated the GSWM background wind field between $\sim 10$ and $120 \mathrm{~km}$ with multi-year monthly averaged HRDI zonal mean zonal wind data. They also updated the ozone climatologies used to parameterize strato-mesospheric tidal forcing (Hagan, 1996) with UARS Halogen Occultation Experiment (HALOE) and Microwave Limb Sounder (MLS) data, but this update did not significantly affect the MLT results. In contrast, the HRDI mean winds profoundly affected the GSWM diurnal and semidiurnal tides in the MLT (10-30\%). Since there are persistent and unresolved differences between HRDI winds, National Meteorological Center (NMC; now called National Centers for Environmental Prediction, NCEP), stratospheric climatologies (Randel, 1992), and an MLT empirical wind model (Portnyagin and Solov'eva, 1992a,b), Hagan et al. (1999) separately quantified the sensitivity of MLT tides to HRDI winds in the stratosphere and MLT. They could not

Copy right (C) The Society of Geomagnetism and Earth, Planetary and Space Sciences (SGEPSS); The Seismological Society of Japan; The Volcanological Society of Japan; The Geodetic Society of Japan; The Japanese Society for Planetary Sciences. identify a systematic difference in either the diurnal or semidiurnal tidal responses. That is, stratospheric zonal mean winds strongly affected some, but not all, MLT tidal fields. MLT zonal mean winds were important in select calculations, but produced negligible effects in others. Further, the impact of the zonal mean wind fields from both regimes varied with season. Hagan et al. (1999) concluded that the accuracy of monthly MLT tidal predictions is critically dependent upon reliable wind climatologies that extend from the ground through the lower thermosphere.

While GSWM results reported by Hagan et al. (1999), hereafter H99, successfully predict many MLT tidal features including the observed seasonal variability of the diurnal and semidiurnal tides, H99 models neither the shorter term (i.e., less than seasonal) nor the interannual tidal variations. Both capabilities are partly precluded by the current parameterization of tropospheric solar heating in the model which is based on 3-month averages of multi-year specific humidity data (Hagan, 1996). The interannual variations in stratomesospheric tidal forcing and mean wind effects can be explored with GSWM given the recent model updates (Hagan et al., 1999), however. That is, we can explore the sensitivity of the MLT tidal response to interannual variations observed in UARS HRDI winds and HALOE/MLS ozone. Burrage et al. (1996) reported on the former, while Randel et al. (1998) discussed the technique used to analyze the ozone data described in this report with results for stratospheric methane and water vapor. In addition to quantifying the dominant annual (AO) and semiannual oscillations (SAO) in the data, these authors also reported on significant quasi-biennial oscillations (QBO) at equatorial and low latitudes that were consistent with independent ground-based wind (Burrage et al., 1996; Garcia et al., 1997) and satellite-borne ozone (Randel and $\mathrm{Wu}, 1996)$ diagnostics.

The top panel in Fig. 1 is an extension of the time series of HRDI equatorial residual (AO and SAO removed) zonal 


\section{HRDI zonal winds at the equator ( $\mathrm{AO}$ and $\mathrm{SAO}$ removed)}

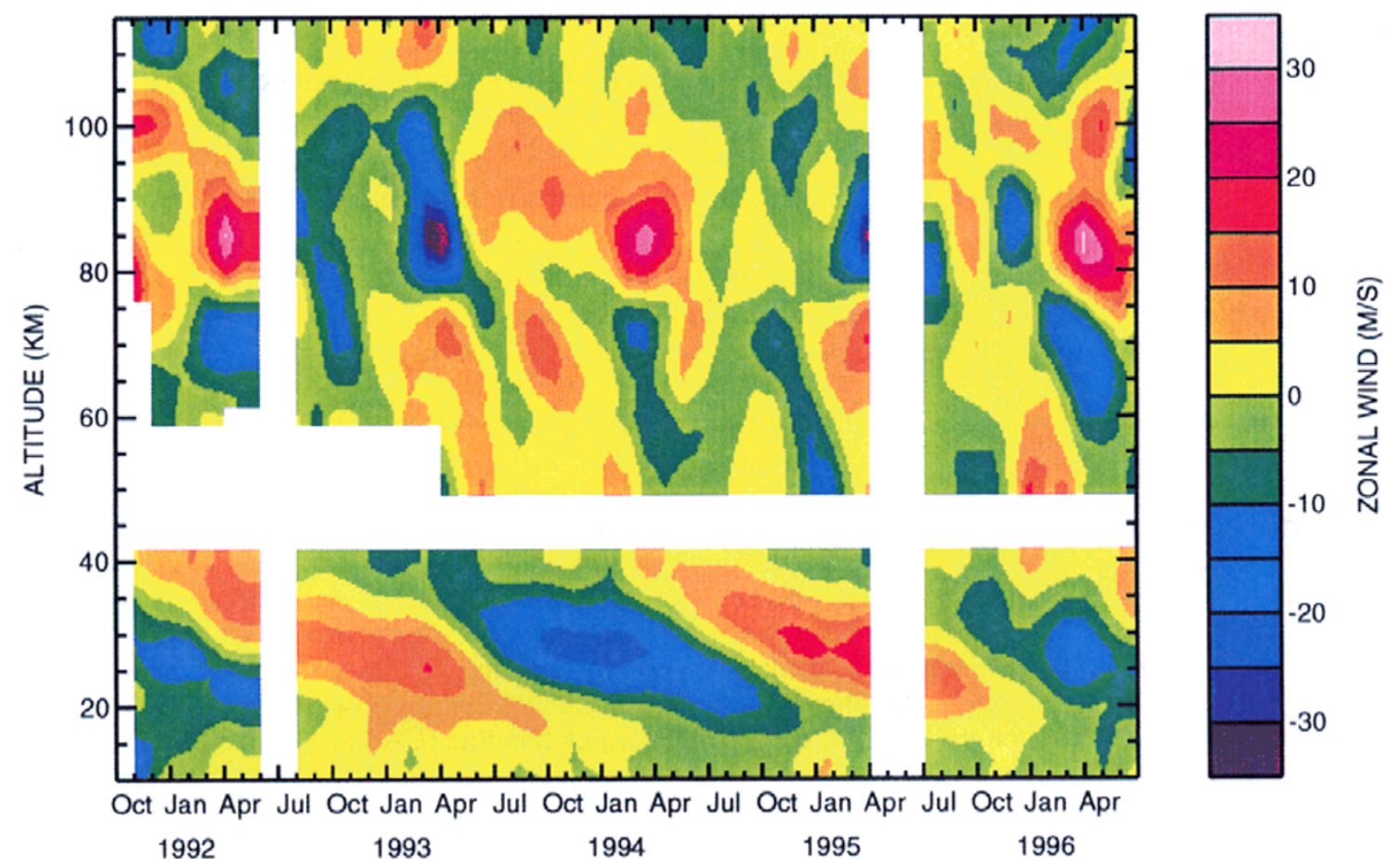

HRDI diurnal $(1,1)$ meridional wind at $95 \mathrm{~km}$ and $20^{\circ} \mathrm{N}$

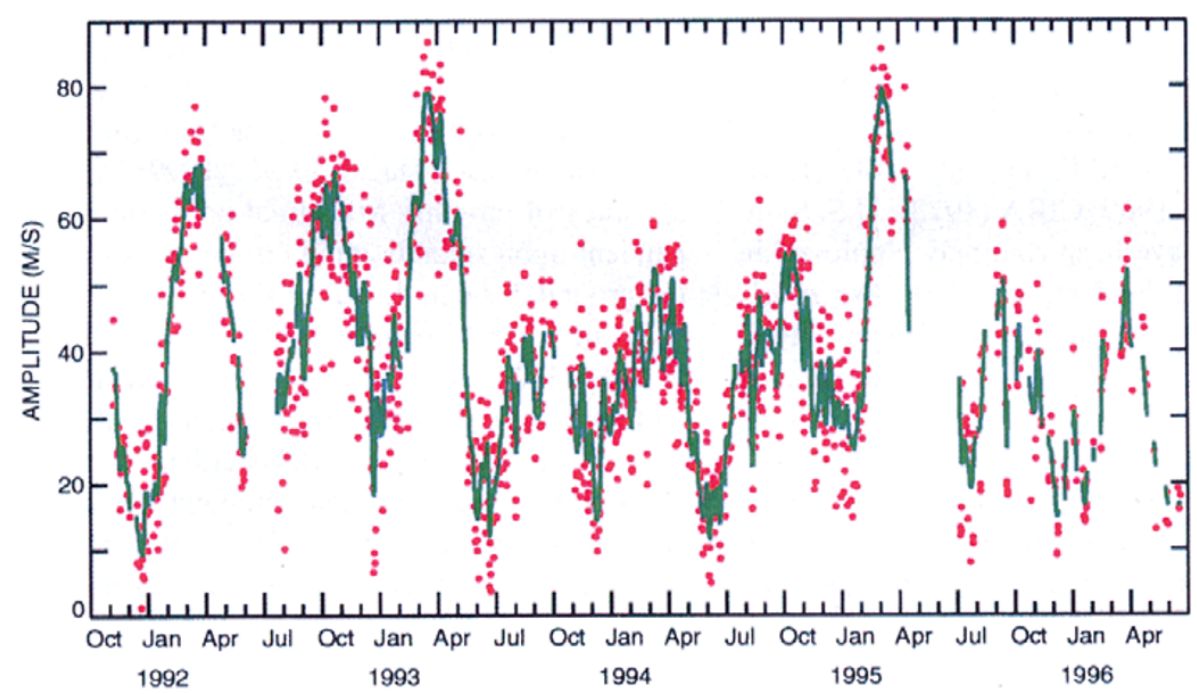

Fig. 1. Altitude-time contours of HRDI equatorial zonal mean zonal winds with the annual and semiannual oscillations removed (top) and northward diurnal tidal amplitudes at $95 \mathrm{~km}$ and $20^{\circ}$ (bottom) versus time from UARS launch through June 1996.

mean zonal winds initially reported by Burrage et al. (1996). The time series of prevailing winds and the techniques used to estimate the AO and the SAO from these data are detailed in the original report (Burrage et al., 1996). We include an extended illustration herein to motivate our GSWM experiment. The mesospheric QBO is evident in the residual winds and out of phase with the stratospheric signature (Fig. 1). Simulations with a global scale spectral model suggest that the mesospheric QBO is driven by selective filtering of smallscale gravity waves $(\mathrm{GW})$ by the underlying winds through which they propagate (Burrage et al., 1996; Mayr et al.,
1997). It is interesting to note that unlike the stratospheric signature which varies smoothly as it descends in altitude with time, the mesospheric QBO signature is characterized by pronounced peaks centered at $\sim 85 \mathrm{~km}$ during April.

In an investigation of the interannual variability of the SAO Garcia et al. (1997) compared 1991-1995 HRDI zonal mean zonal winds with diurnal mean zonal wind measurements made with the medium frequency (MF) radar at Christmas Island $\left(2^{\circ} \mathrm{N} ; 157^{\circ} \mathrm{W}\right)$. They reported that the striking relationship between stratospheric and mesospheric QBO equatorial winds (e.g., top of Fig. 1) reported by Burrage et al. (1996) 
was less evident in the 1990-1992 Christmas Island data. Garcia et al. (1997) supported the plausibility of GW filtering effects in interpreting the observed interannual variability of the mesospheric SAO, but suggested that intermediate-scale (zonal wavenumbers 5-25) Kelvin and inertia-gravity waves may also play a significant role (Sassi and Garcia, 1994).

In this brief report we exploit the aforementioned UARS QBO wind (top of Fig. 1) and ozone data (not illustrated) to conduct numerical experiments with the GSWM. Our experiments are an extension of those reported by Hagan et al. (1992) who quantified the effects of the stratospheric wind QBO on the upward propagating semidiurnal tide. Using a precursor of GSWM Hagan et al. (1992) reported significant semidiurnal variations of measurable magnitudes (5-20 $\mathrm{m} / \mathrm{s}$ ) that were due to the QBO in stratospheric zonal winds and largest in the MLT wind field at high latitudes. They concluded that their semidiurnal tidal signatures were uncorrelated with the zonally-averaged wind direction at the 40 mbar level (i.e., the so-called phase of the QBO), because the semidiurnal response in the MLT was affected by the aggregate wind changes over the entire range of stratospheric altitudes. Like Hagan et al. (1992) we investigate the effects of the QBO in stratospheric winds on the MLT tidal response. However, we focus on the diurnal component and also explore the QBO effects due to stratospheric ozone and mesospheric winds. In the following section we describe the interannual variability of the diurnal tide that has been observed in HRDI winds which partly motivates our numerical experiments.

\section{Motivation}

The long term variability of the diurnal tide observed by HRDI at the latitude where the northward wind component peaks (near $+/-20^{\circ}$ and $95 \mathrm{~km}$ ) was initially described by Burrage et al. (1995). The time series has been extended through June 1996 for this report (bottom of Fig. 1). Daily (points) as well as weekly-averaged (curve) tidal estimates illustrate the pronounced SAO in northward diurnal wind amplitude which may be attributable to seasonally variable GW drag and eddy dissipation on the diurnal tide (Burrage et al., 1995; Geller et al., 1997; Hagan et al., 1999; Meyer, 1999). There is also evidence of pronounced interannual variability of the diurnal tide. For example, tidal amplitudes during 1992 and the first quarter of 1993 are about $20 \mathrm{~m} / \mathrm{s}$ larger than those observed in the latter part of 1993 and 1994. Interestingly, the tidal SAO is notably weaker during the latter period. There is also an arguable suggestion of a QBO in the tidal diagnostics. That is, the amplitudes in April 1993 and 1995 are larger than those observed in April 1992 and April 1994. Admittedly, the April 1992 and April 1994 amplitudes are not comparable, since the aforementioned longer-term variation dominates the evolution of tidal amplitude during the intervening period.

Recently, Vincent et al. (1998) analyzed a 12-year time series of MF radar measurements made at Adelaide, Australia $\left(35^{\circ} \mathrm{S} ; 138^{\circ} \mathrm{E}\right)$ and reported that March/April and May/June diurnal tidal amplitudes are correlated with the QBO in stratospheric zonal mean winds. They found that diurnal wind amplitudes were larger (smaller) than the multi-year averaged values when the winds at the 30 mbar level over
Singapore were eastward (westward). The results of comparative Kauai, Hawaii $\left(22^{\circ} \mathrm{N} ; 160^{\circ} \mathrm{W}\right)$ and Christmas Island MF data analyses were less convincing, in part because these time series were significantly shorter ( $\sim 6$ years). They reported that the Christmas Island data analysis resulted in the "appearance" of an association similar to that found for Adelaide, but only in the zonal wind component (Vincent $e t$ al., 1998).

Plausible sources of the diurnal tidal variability observed on any time scale include variations in tidal forcing, dissipation, wave-tide interactions, tide-mean flow interactions, and unresolved tidal sources. H99 models the observed diurnal tidal SAO illustrated in at the bottom of Fig. 1, since it includes seasonally variable forcing, dissipation, and mean flow effects (Hagan et al., 1999). Given evidence ofQBO signatures in equatorial winds (Fig. 1) and strato-mesospheric ozone (e.g., Randel and Wu, 1996) which is a well-known tidal source, we can explore this subset of plausible sources of tidal variability with GSWM. We use monthly averaged HRDI and HALOE/MLS data from April 1993 and 1994 to explore these effects.

\section{GSWM QBO Experiments}

GSWM is a 2-dimensional linearized model that was recently described by Hagan et al. (1999). Briefly, it solves the extended Navier-Stokes equations for tidal and planetary wave perturbations as a function of latitude and altitude for a specified wave periodicity and zonal wavenumber. MSISE-90 zonal mean temperatures (Hedin, 1991), Groves $(1985,1987)$ semi-empirical model of tropospheric winds, and HRDI 6-year monthly averaged zonal mean zonal wind climatologies are used to specify GSWM background atmosphere. Migrating tidal forcing is parameterized by Groves (1982) in the troposphere, while HALOE/MLS 6year monthly averaged ozone climatologies and the Strobel (1978) scheme are used to account for strato-mesospheric heating. GSWM includes molecular and eddy diffusivity effects, an effective Rayleigh friction to account for GW stress, and parameterizations for ion drag and Newtonian cooling effects. The reader is referred to Hagan et al. $(1995,1999)$ and to the GSWM site (http://www.hao.ucar.edu/public/research/ tiso/gswm/gswm.html) to learn more about the model.

The mesospheric wind QBO appears most pronounced during April, so we focus on this month. We modify the H99 wind background and ultraviolet tidal heating rates with April 1993 and 1994 UARS data, since there were dramatic differences in the background fields and in the diurnal tide observed by HRDI during those periods.

\subsection{Zonal mean zonal wind QBO effects}

For the GSWM experiments designed to test QBO wind effects, April 1993 and April 1994 HRDI zonal wind measurements made between $+/-20^{\circ}$ were spliced into the standard H99 background. The resultant climatologies are respectively illustrated at the top of Figs. 2 and 3, while the bottom panels illustrate the differences between these winds and the standard April HRDI wind climatology based on the 6-year mean wind averages. During both years mean wind differences are largest in the mesopause region, but 1993 westward residuals which are as large as $40 \mathrm{~m} / \mathrm{s}$ (bottom of Fig. 2) exceed 1994 eastward residuals (bottom of Fig. 3) by more 


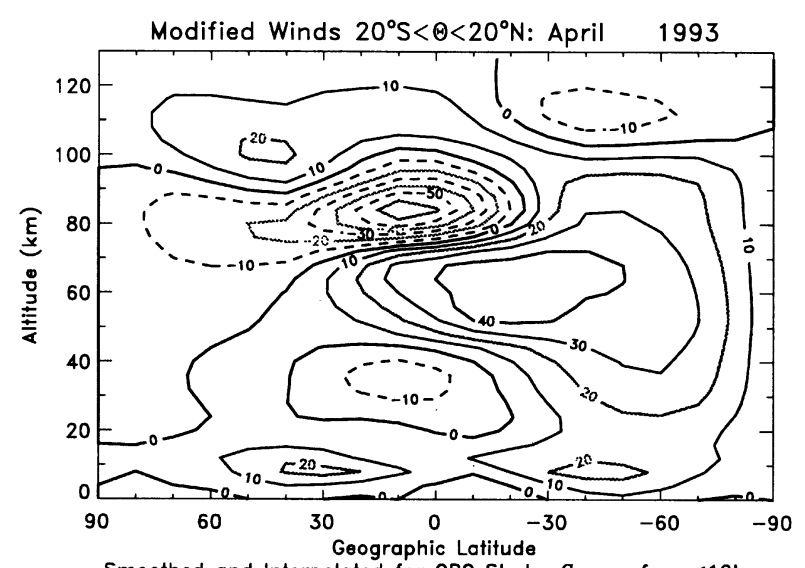

Smoothed and Interpolated for QBO Study; Groves for $z<12 \mathrm{~km}$

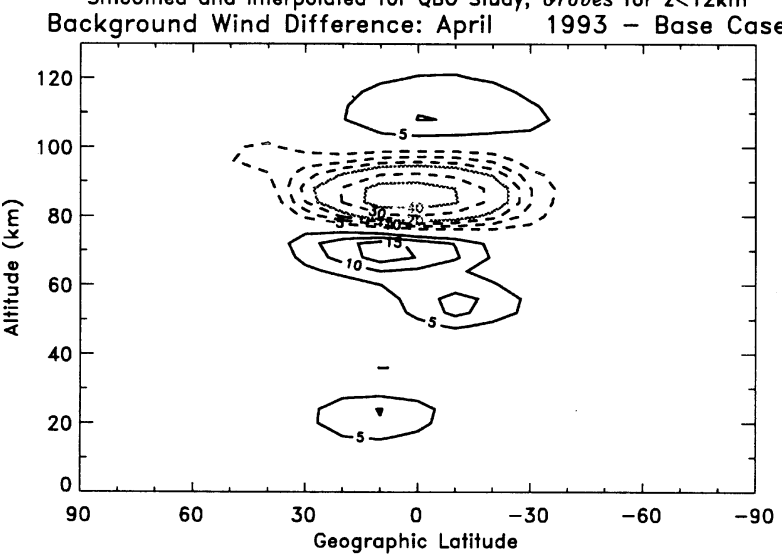

Fig. 2. GSWM background winds based on April 1993 HRDI measurements (top) and the differences between these data and the 6-year climatologies (bottom). See text for details.

than a factor of 2. Stratospheric wind differences are much smaller and within $10 \mathrm{~m} / \mathrm{s}$.

We used standard tidal forcing and ran GSWM to quantify the effects of the mean wind differences (Figs. 2 and 3) on the diurnal tide. Figure 4 illustrates the difference between the April 1993 results and the standard H99 April diurnal tide (Hagan et al., 1999). Hereafter, we refer to the latter as the base case. The 1993 zonal (top) and meridional (middle) diurnal winds are smaller than the base case results by $\sim 20 \mathrm{~m} / \mathrm{s}$ and $30 \mathrm{~m} / \mathrm{s}$, respectively, while peak temperature amplitudes are more than $10^{\circ} \mathrm{K}$ smaller (bottom). The comparable April 1994 and base case differences (not illustrated) are negligibly small $\left(<5 \mathrm{~m} / \mathrm{s} ;<5^{\circ} \mathrm{K}\right)$. So, the GSWM April 1994 results are also larger than the April 1993 results. Conversely, the northward diurnal amplitude observed by HRDI was $\sim 30 \mathrm{~m} / \mathrm{s}$ larger in April 1993 than it was in 1994 (bottom of Fig. 1). Therefore, the effect of the variable equatorial and low latitude zonal mean winds in GSWM is exactly opposite to the interannual tidal variability observed by HRDI. The GSWM calculations are also inconsistent with the correlation reported by Vincent et al. (1998), since the eastward residual in the 1993 stratospheric zonal mean wind field (Fig. 2) is associated with smaller MLT diurnal wind amplitudes in GSWM (Fig. 4).
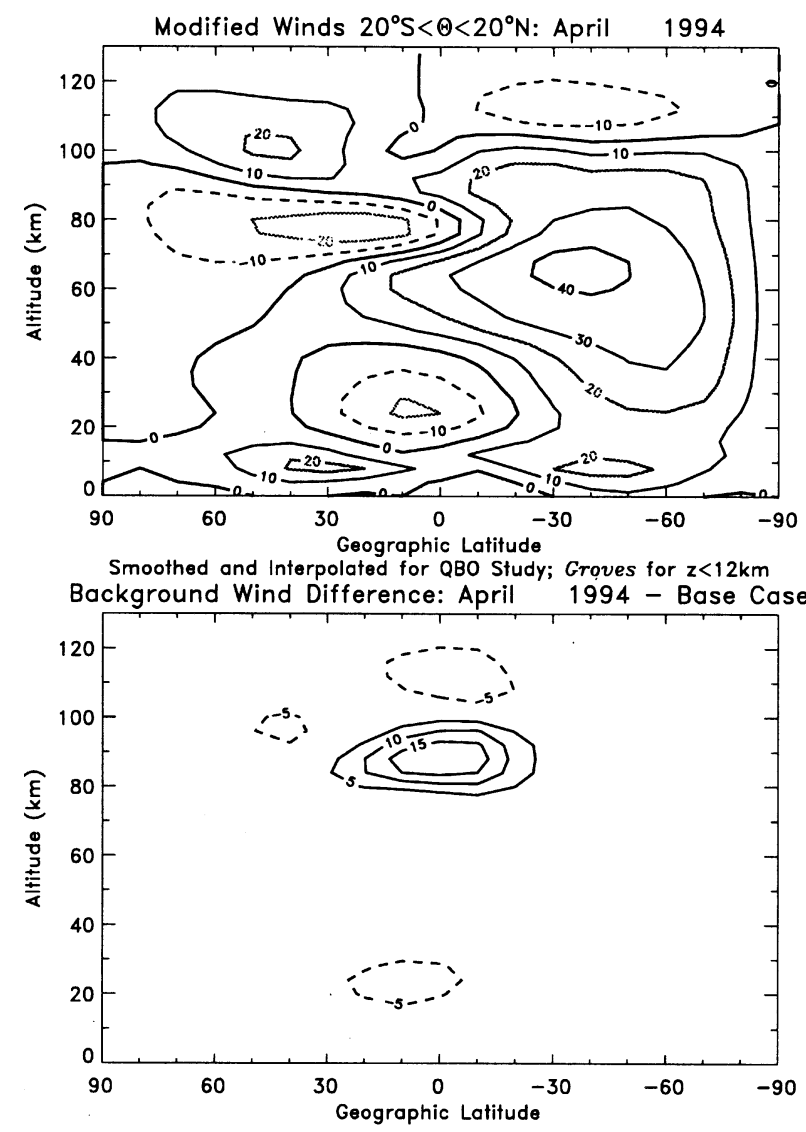

Fig. 3. Same as Fig. 2 except for April 1994.

\subsection{Ozone QBO effects}

Strato-mesospheric ozone absorbs solar ultraviolet (UV) radiation exciting migrating tidal harmonics. It is reasonable to assume, therefore, that the QBO observed in ozone density (e.g., Randel and Wu, 1996) may drive a QBO in the diurnal tidal response. We calculate the differences between April 1993, April 1994, and the 6-year averaged April HALOE/MLS ozone densities and their effects on the diurnal tide calculated with GSWM.

Figure 5 illustrates April 1993 HALOE/MLS ozone density as a function of latitude and altitude (top), with contours of differences between these and 6-year April averages that constitute the H99 ozone base case. All ozone climatologies were formulated using HALOE data below $50 \mathrm{~km}$ and MLS data aloft (after Hagan et al., 1999). During April ozone densities are largest near the equator and at $\sim 35 \mathrm{~km}$ in altitude (top of Fig. 5). In 1993 the peak densities were comparatively larger than the 6-year mean values (bottom of Fig. 5). In contrast, the peak values were smaller than the base ozone climatology during April 1994 (not shown), but the location and absolute magnitudes of the peak differences are similar to those shown in Fig. 5. Importantly, there is no interannual variability near the altitude where peak tidal forcing occurs ( $\sim 50 \mathrm{~km})$ (Hagan, 1996). Thus, the QBO in ozone density has only a minimal effect on the diurnal tide in the MLT as seen in the GSWM results illustrated in Fig. 6. Differences between the April 1993 ozone run and the H99 April base case are only of the order of a few $\mathrm{m} / \mathrm{s}$ in wind speed and 

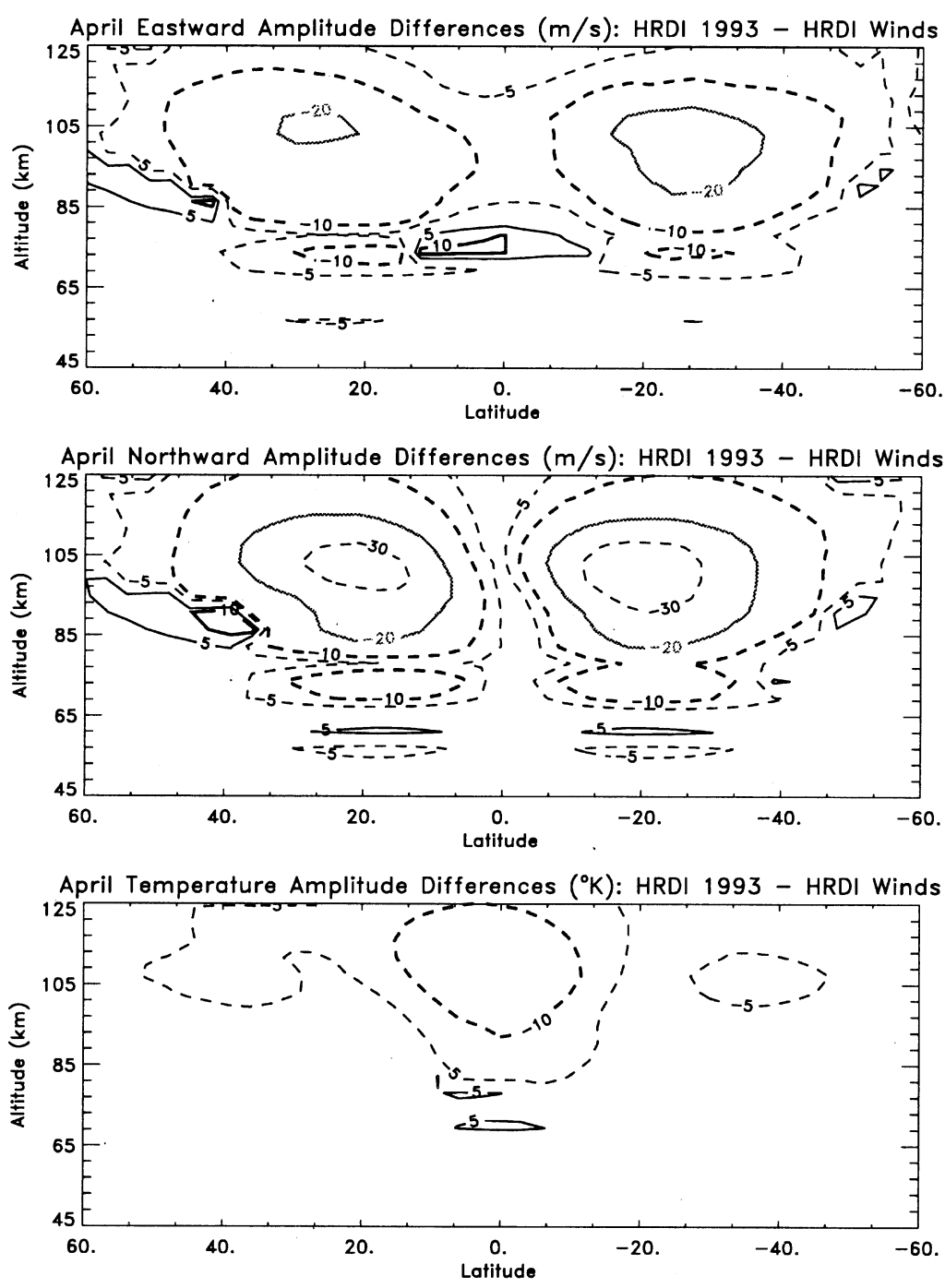

Fig. 4. Differences in GSWM diurnal tidal amplitudes for the eastward wind (top), northward wind (middle), and temperature (bottom) due to the 1993 HRDI background wind effects illustrated in Fig. 2.

${ }^{\circ} \mathrm{K}$ in temperature. We conclude that variable ozone forcing cannot explain the variations in the diurnal tide observed by HRDI during April 1993 and 1994.

\section{Discussion}

Many authors have developed independent analytic formulations which elucidate the diurnal tidal response to mean wind and/or dissipative effects (e.g., Lindzen, 1972; Hines, 1974, 1989; Richmond, 1975; Forbes and Vincent, 1989). Despite their inherent simplifications the more sophisticated of these formulations provide insight into some of the features of the full-wave model results reported herein. We note that the comparatively more simplistic theories developed for an equatorial (non-rotating) atmosphere (e.g., Lindzen, 1972; Hines, 1974) significantly underestimate dissipative effects at higher latitudes and are therefore inappropriate for the interpretation of global MLT tidal responses (Forbes and Vincent, 1989; Hines, 1989).

There are 3 notable characteristics of the GSWM difference fields illustrated in Fig. 4. First, the base case results are systematically larger than the April 1993 tidal response. Second, the aforementioned differences are confined to low and middle latitudes. Third, the difference fields peak at $\sim 100 \mathrm{~km}$. While the magnitude of the tidal differences cannot be understood within an analytic context, the 2 remaining characteristics of our results may be inferred from analytic theory. We discuss these features in the context of the Forbes and Vincent (1989) results which we highlight in the paragraphs below. We refer the reader to Forbes and Vincent (1989) for details and to Hines (1989) who was motivated by these authors to discuss similar results in a different mathematical context.

Forbes and Vincent (1989) developed an analytic formulation to investigate the diurnal propagating tide in the presence of zonal mean winds and dissipation. In doing so they quantified resultant distortions of the classical (i.e., windless and dissipationless) diurnal tidal solution. First they investigated the impact of mean eastward wind $(U)$ on the latitudinal structure of the propagating diurnal tidal solution. For a simple wind field of the form $U=U_{\mathrm{o}} \sin \theta$ and $U_{\mathrm{o}}=50 \mathrm{~m} / \mathrm{s}$ 

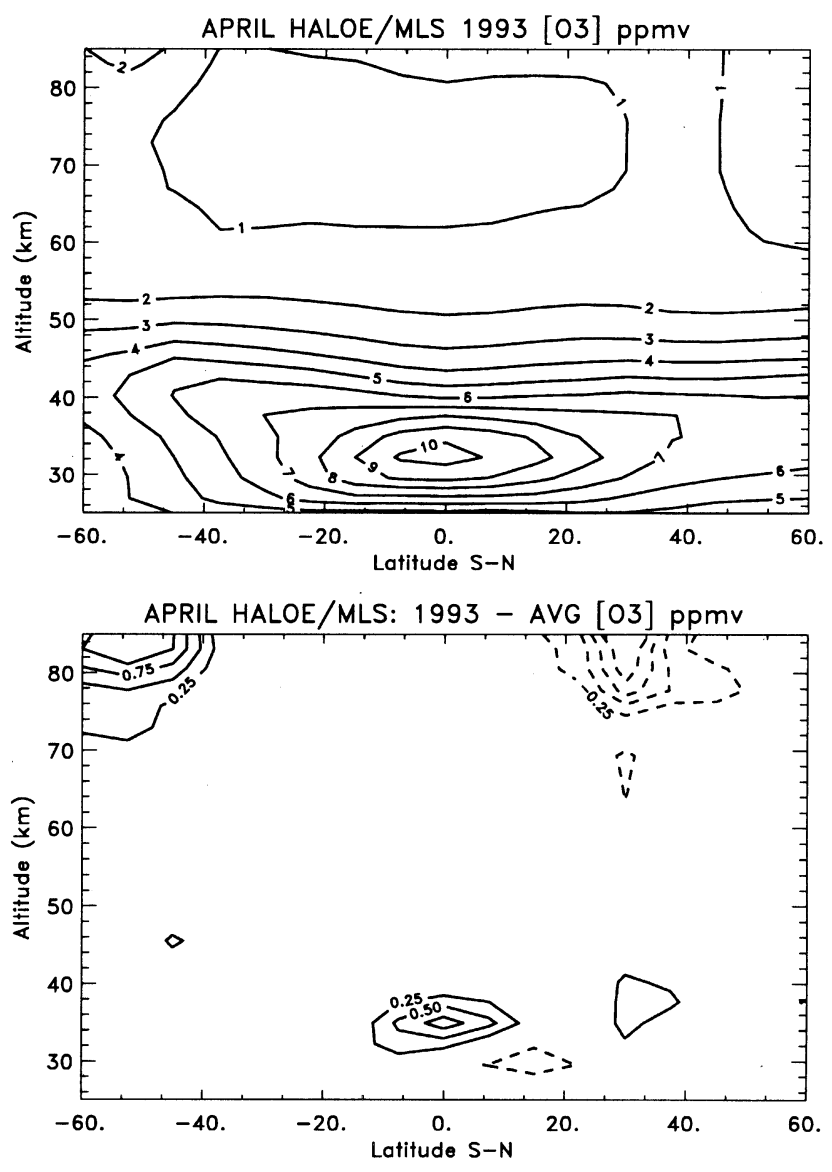

Fig. 5. GSWM background ozone based on April 1993 HALOE and MLS measurements (top) and the differences between these data and the 6-year climatologies (bottom). See text for details.

they reported amplification and broadening of the classical expansion function where $U>0$ and a narrowed and diminished response where $U<0$. For more realistic $U$ both the absolute magnitude and wind direction characterize the expansion function distortion at a given altitude. As illustrated in figure 8 in Forbes and Vincent (1989) the broadening may be relatively more pronounced at high latitudes. However, the diurnal tidal response is comparatively small there. Consequently, the effects of $U$ on the latitudinal structure of the diurnal tide are most significant at low and middle latitudes where the tidal response is largest. This result is consistent with the differences due to $U$ that we illustrate in Fig. 4.

Forbes and Vincent (1989) also quantified the effects of $U$ on the vertical structure of the diurnal tidal solution. Briefly, $h^{\prime}=h(1+\beta)^{4}$ for $\beta=U / C_{\mathrm{o}} \sin \theta$, where $h=\Omega^{2} a^{2} / 36 g$ is the equivalent depth; $C_{\mathrm{o}}$ represents the eastward phase speed of the wave at the equator $(\sim 456 \mathrm{~m} / \mathrm{s}) ; \theta$ is colatitude; $\Omega$ is the Earth's rotation rate; and $a$ is the mean Earth radius. Thus, $h$ is real and it becomes larger (smaller) for eastward (westward) mean winds. Since $k_{z}=\sqrt{\omega_{\mathrm{B}}^{2} / g h^{\prime}-1 / 4 H^{2}}$ where $\omega_{\mathrm{B}}$ is the Brunt-Väisälä frequency; $g$ is gravitational acceleration; $H$ is the local scale height, and $k_{z}$ is inversely proportional to the vertical wavelength of the diurnal propagating tide, $\lambda_{z}$, one can readily infer that eastward (westward) mean winds effectively lengthen (shorten) $\lambda_{z}$ (Forbes and Vincent, 1989).

We note that our diurnal difference fields (Fig. 4) are smoothly varying, rather than alternating in sign as would be typical of significant $\lambda_{z}$ distortion. We attribute this absence to the similarities in $U$ employed in our calculations. Earlier and in the discussion above we focused on the significant differences between the April 1993, April 1994, and April base case background wind climatologies (Figs. 2 and 3). In order to better understand their impacts on the diurnal tide, it is equally important to note some striking similarities in the 3 background wind fields. That is, in all cases the zonal winds are eastward throughout the southern hemisphere from the ground to $\sim 100 \mathrm{~km}$ and in the northern hemisphere at tropospheric and lower thermospheric altitudes. Further, the zonal winds are westward in the lower thermospheric southern hemisphere and at low (all) latitudes in the northern hemisphere at stratospheric (mesopause region) altitudes.

There are GSWM MLT diurnal tidal difference fields described elsewhere (e.g., Hagan et al., 1999) that exhibit $\lambda_{z}$ distortion at localized regions in the model regime. Such distortion occurs if there is a jet in one empirical background that is absent in the other, or if one model predicts eastward winds and the other predicts westward winds in some localized region. Notably, when large $\lambda_{z}$ differences do exist, they introduce significant structure into the resultant diurnal tidal difference fields wherein no one wave is systematically larger than the other (e.g., Hagan et al., 1999).

Forbes and Vincent (1989) also demonstrated that the inclusion of momentum dissipation in the form of an effective Rayleigh friction $(\alpha)$ yields a complex vertical wavenumber, $k_{z}=k_{\mathrm{r}}+\mathrm{i} k_{\mathrm{i}}=\sqrt{\omega_{\mathrm{B}}^{2} / g h^{*}-1 / 4 H^{2}}$, and a complex equivalent depth, $h^{*}=\Omega^{2} a^{2} / 36 g(1+\mathrm{i} \alpha / \Omega)^{4}$. Since $k_{\mathrm{i}}$ critically affects the amplitude profile, Forbes and Vincent demonstrated that the effects of dissipation offset the exponential growth of the propagating diurnal tide. The GSWM difference fields reflect the offset between dissipation and exponential growth (Fig. 4) that also characterize both the April 1993 and base case results (Hagan et al., 1999) which are not illustrated herein but peak at $\sim 100 \mathrm{~km}$.

As previously suggested, the assumptions inherent in the Forbes and Vincent (1989) formulation preclude its use for further interpretation of our results. While GSWM dissipation does include an effective Rayleigh friction to account for GW drag effects, the formulations for other dissipative terms are more complicated. The GSWM parameterizations of molecular viscosity $\left(\mu_{\mathrm{o}}\right)$ and eddy diffusivity $\left(v_{\text {eddy }}\right)$ are of particular relevance. The associated terms in the GSWM horizontal momentum and energy equations involve the explicit calculation of the divergence of momentum and energy flux due to molecular and eddy diffusion (Hagan et al., 1999). They are $1 / \rho_{\mathrm{o}} \partial / \partial z\left(\mu_{\mathrm{o}}+\rho_{\mathrm{o}} v_{\text {eddy }}\right) \partial / \partial z U^{\prime}$ and $1 / \rho_{\mathrm{o}} \partial / \partial z\left(\mu_{\mathrm{o}}+\right.$ $\left.\rho_{\mathrm{o}} v_{\text {eddy }}\right) \partial / \partial z \delta T$, respectively, for $U^{\prime}=\left(u^{\prime}, v^{\prime}\right)$, the zonal $\left(u^{\prime}\right)$ and meridional $\left(v^{\prime}\right)$ tidal fields; $\delta T$, the tidal temperature; $\rho_{\mathrm{o}}$, zonal mean density; and $z$, altitude. These terms clearly indicate that there is a feedback between the modifications to the tide that are attributable to mean wind differences (i.e., vertical wavelength distortions) and the concomitant modifications attributable to dissipative effects. This feedback is neglected in any analytic formulation and must account for 

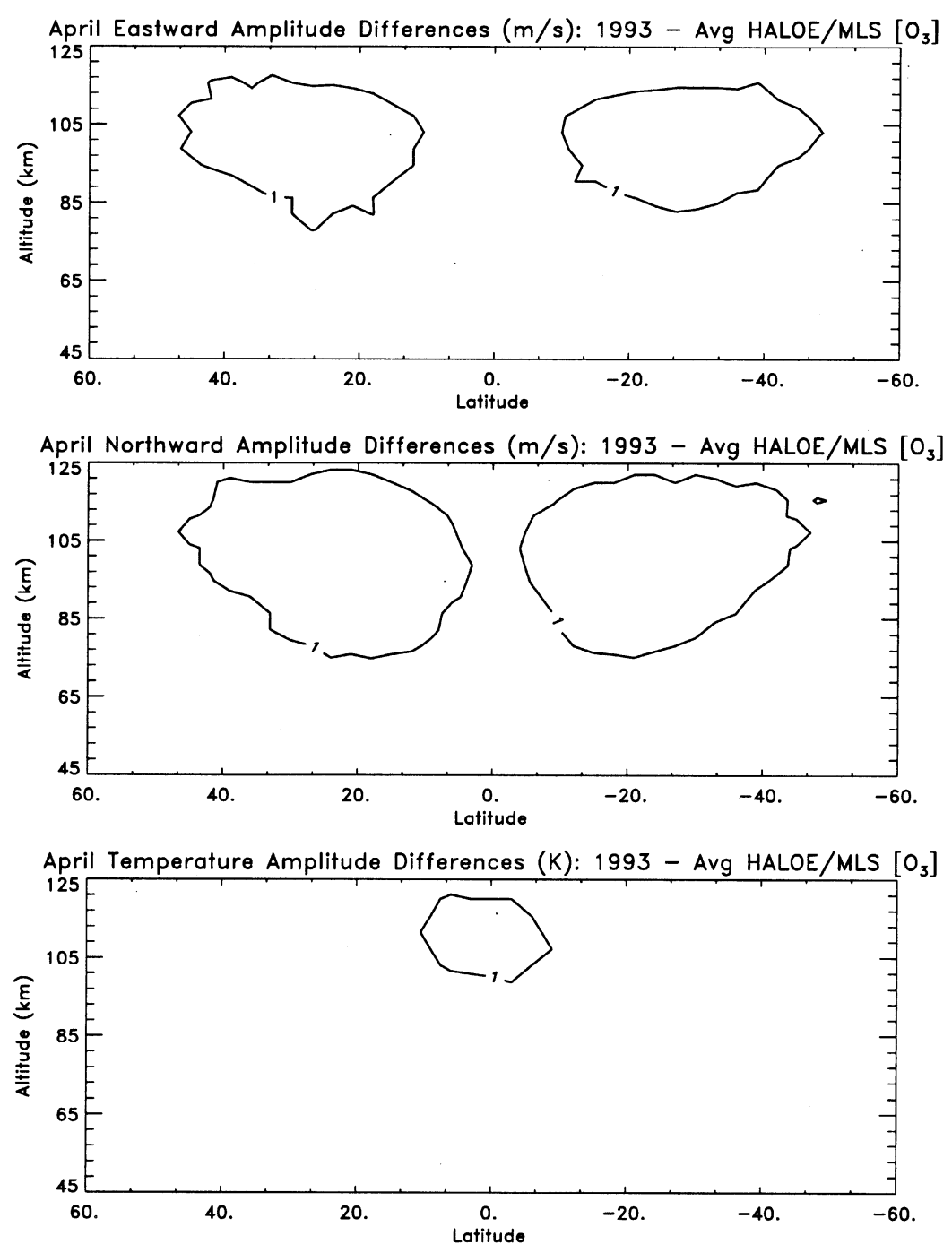

Fig. 6. Differences in GSWM diurnal tidal amplitudes for the eastward wind (top), northward wind (middle), and temperature (bottom) due to the 1993 HALOE and MLS ozone effects illustrated in Fig. 5.

the magnitude of GSWM difference fields like those illustrated in Fig. 4.

In their report on non-migrating tidal studies with a linear tidal model, Ekanayake et al. (1997) present results which further support the aforementioned claim. Ekanayake et al. (1997) quantify and interpret the effects of realistic tidal dissipation on the diurnal tide in the presence of mean winds. They note that diurnal tidal amplitudes are larger in atmospheric regions where the Doppler shifted frequency of the tide, $\hat{\sigma}=\sigma+s U / a \sin \theta$, is comparatively large; $\sigma$ is the diurnal frequency and $s$ is the zonal wavenumber. They attribute this behavior to the comparative effects of dissipation on tides in the presence of $U$ and note that it is harder (easier) to dissipate a higher (lower) frequency wave for vertical wavelengths that are of comparable order. The Ekanayake et al. (1997) result suggests that the MLT migrating $(s=1)$ diurnal tidal response should be comparatively large when the wave undergoes dissipation in regions of large westward zonal mean zonal winds. The GSWM signatures illustrated in Figs. 2 and 4 bear evidence of such a response. The base case background winds are comparatively more westward than the April 1993 winds (bottom of Fig. 2) in the equatorial and low latitude MLT (ca. 80-100 km). As expected (Ekanayake et al., 1997), the base case migrating diurnal tidal response is comparatively larger than the April 1993 response in this same regime (Fig. 4) where GSWM tidal dissipation effects are strongest. The global nature of the tide accounts for the poleward extension of this response.

\section{Summary and Conclusion}

Two plausible sources of MLT tidal variability are variations in zonal mean zonal winds throughout the atmosphere and variable forcing due to absorption of UV radiation by ozone. The UARS HRDI and HALOE/ MLS instruments provide evidence of a QBO in both fields. There is also the suggestion of a QBO in the MLT diurnal tide observed by HRDI (bottom of Fig. 1). We use 6-year averaged UARS climatologies and monthly averaged data from the April 1993 and April 1994 in the GSWM to quantify the effects of the QBO in zonal mean winds and ozone on the diurnal tide. We 
find the QBO in ozone produces negligible MLT diurnal tidal effects, since the important ozone OBO variations occur below the altitude of peak tidal forcing. The pronounced QBO variations in zonal mean wind significantly affect the GSWM MLT diurnal tidal response ( $\sim 40 \%$ ), but the GSWM results explain neither the interannual tidal variations observed by HRDI nor the correlations between the phase of the stratospheric QBO and Adelaide diurnal wind effects (Vincent et al., 1998). That is, April 1993 GSWM northward wind amplitudes are smaller than those calculated with the April 1994 background which is opposite to what was observed by HRDI and the 1993 eastward stratospheric mean wind residuals are associated with a comparatively smaller MLT tidal response. We conclude that neither of the plausible sources of QBO tidal variability that we explored with the GSWM numerical experiments reported herein can explain the observed interannual variability of the diurnal tide. Therefore, the observed tidal variability must be due to an alternate tidal source (e.g., tropospheric latent heating associated with convective activity) or to a long-term variation in tidal dissipation.

Acknowledgments. The authors thank Gang Lu and Art Richmond for comments on the initial draft of this report. The National Center for Atmospheric Research (NCAR) is sponsored by NSF. The efforts of M. E. Hagan were supported in part by the NSF CEDAR program. M. E. Hagan and J. Hackney acknowledge NASA grants S-41353F and S-10105X to NCAR. The efforts of M. D. Burrage were supported by NASA grant NAG5-4007. J. M. Forbes and X. Zhang received support from NSF grant ATM-9728993 to the University of Colorado.

\section{References}

Aso, T., T. Y. Nonoyama, and S. Kato, Numerical simulation of semidiurnal atmospheric tides, J. Geophys. Res., 86, 11,388-11,400, 1981.

Batten, E. S., Wind systems in the mesosphere and lower ionosphere, $J$. Meteorol., 18, 283-291, 1961.

Burrage, M. D., M. E. Hagan, W. R. Skinner, D. L. Wu, and P. B. Hays, Long-term variability in the solar diurnal tide observed by HRDI and simulated by the GSWM, Geophys. Res. Lett., 22, 2641-2644, 1995.

Burrage, M. D., R. A. Vincent, H. G. Mayr, W. R. Skinner, N. F. Arnold, and P. B. Hays, Long-term variability in the equatorial mesosphere and lower thermosphere zonal wind, J. Geophys. Res., 101, 12,847-12,854, 1996.

Ekanayake, E. M. P., T. Aso, and S. Miyahara, Background wind effect on propagation of nonmigrating diurnal tides in the middle atmosphere, $J$. Atmos. Sol.-Terr. Phys., 59, 401-429, 1997.

Forbes, J. M., Atmospheric tides, 1, Model description and results for the solar diurnal component, J. Geophys. Res., 87, 5222-5240, 1982.

Forbes, J. M. and M. E. Hagan, Diurnal propagating tide in the presence of mean winds and dissipation: A numerical investigation, Planet. Space Sci., 36, 579-590, 1988 .

Forbes, J. M. and F. Vial, Monthly simulation of the solar semidiurnal tide in the mesosphere and lower thermosphere, J. Atmos. Terr. Phys., 51, 649-661, 1989.

Forbes, J. M. and R. A. Vincent, Effects of mean winds and dissipation on the diurnal propagating tide: An analytic approach, Planet. Space Sci., 37, 197-209, 1989.

Garcia, R. R., T. J. Dunkerton, R. S. Lieberman, and R. A. Vincent, Climatology of the semiannual oscillation of the tropical middle atmosphere, J. Geophys. Res., 102, 26,019-26,032, 1997.

Geller, M. A., B. V. Khattatov, V. A. Yudin, and M. E. Hagan, Modeling the diurnal tide with dissipation derived from UARS/HRDI measurements, Ann. Geophys., 15, 1198-1204, 1997.

Groves, G. V., Hough components of water vapor heating, J. Atmos. Terr. Phys., 44, 281-290, 1982.

Groves, G. V., A global reference atmosphere from 18 to $80 \mathrm{~km}, A F G L$ Report TR-85-0129, 1985.
Groves, G. V., Final scientific report, AFOSR Report 84-0045, 1987.

Hagan, M. E., Comparative effects of migrating solar sources on tidal signatures in the middle and upper atmosphere, J. Geophys. Res., 101, 21,21321,222, 1996.

Hagan, M. E., F. Vial, and J. M. Forbes, Evidence of variability in upward propagating semidiurnal tides due to effects of QBO in the lower atmosphere, J. Atmos. Terr. Phys., 54, 1465-1474, 1992.

Hagan, M. E., J. M. Forbes, and F. Vial, On modeling migrating solar tides, Geophys. Res. Lett., 22, 893-896, 1995.

Hagan, M. E., M. D. Burrage, J. M. Forbes, J. Hackney, W. J. Randel, and X. Zhang, GSWM-98: Results for migrating solar tides, J. Geophys. Res., 104, 6813-6828, 1999.

Hedin, A. E., Extension of the MSIS thermosphere model into the middle and lower atmosphere, J. Geophys. Res., 96, 1159-1172, 1991.

Hines, C. O., The upper atmosphere in motion, in Geophys. Mono., No. 18, 1027 pp., American Geophysical Union, Washington, DC, 1974.

Hines, C. O., Latitudinal variation of tidal dissipation and upward propagation, Planet. Space Sci., 37, 669-683, 1989.

Kantor, A. J., and A. E. Cole, Zonal and meridional winds to 120 kilometers, J. Geophys. Res., 69, 5131-5140, 1964.

Lindzen, R. S., Equatorial planetary waves in shear: Part II, J. Atmos. Sci., 29, 1452-1463, 1972.

Lindzen, R. S. and S. S. Hong, Effects of mean winds and horizontal temperature gradients on solar and lunar semidiurnal tides in the atmosphere, J. Atmos. Sci., 31, 1421-1466, 1974.

Mayr, H. G., J. G. Mengel, C. O. Hines, K. L. Chan, N. F. Arnold, C. A. Reddy, and H. S. Porter, The gravity wave Doppler spread theory applied in a numerical spectral model of the middle atmosphere, 2, Equatorial oscillations, J. Geophys. Res., 102, 26,093-26,105, 1997.

Meyer, C. K., Gravity wave interactions with the diurnal propagating tide, J. Geophys. Res., in press, 1999.

Murgatroyd, R. J., Winds in the mesosphere and lower thermosphere, Proc. Roy. Soc. London, A288, 575-589, 1965.

Murphy, C., Seasonal variations of ionospheric wind over Barbados, J. Geophys. Res., 74, 339-367, 1969.

Portnyagin, Yu. I. and T. V. Solov'eva, An empirical model of the meridional wind in the mesopause-lower thermosphere, Part 1, A mean monthly empirical model, Russian J. Met. and Hydr., 10, 28-35, 1992a.

Portnyagin, Yu. I. and T. V. Solov'eva, An empirical model of the meridional wind in the mesopause/lower thermosphere, Part 2, Height-latitude features of basic components of meridional wind seasonal variations, Russian J. Met. and Hydr., 11, 29-36, 1992b.

Randel, W. J., Global atmospheric circulation statistics, 1000-1 mb, National Center for Atmospheric Research Technical Note 366, 1992.

Randel, W. J. and F. Wu, Insolation of ozone QBO in SAGE II data by singular-value decomposition, J. Atmos. Sci., 53, 2546-2559, 1996.

Randel, W. J., F. Wu, J. M. Russell III, A. Roche, and J. Waters, Seasonal cycles and QBO variations in stratospheric $\mathrm{CH}_{4}$ and $\mathrm{H}_{2} \mathrm{O}$ observed in UARS HALOE data, J. Atmos. Sci., 55, 163-185, 1998.

Richmond, A. D., Energy relations of atmospheric tides and their significance to approximate methods of solutions of tides with dissipative forces, J. Atmos. Sci., 32, 980-987, 1975.

Sassi, F. and R. R. Garcia, A one-dimensional model of the semiannual oscillation driven by convectively forced gravity waves, J. Atmos. Sci., 51, 3167-3182, 1994.

Strobel, D. F., Parameterization of the atmospheric heating rate from 15 to $120 \mathrm{~km}$ due to $\mathrm{O}_{2}$ and $\mathrm{O}_{3}$ absorption of solar radiation, J. Geophys. Res., $\mathbf{8 3}, 6225-6230,1978$.

Vial, F., Numerical simulations of atmospheric tides, J. Geophys. Res., 91, 8955-8969, 1986.

Vincent, R. A., S. Kovalam, D. C. Fritts, and J. R. Isler, Long-term MF radar observations of solar tides in the low-latitude mesosphere: Interannual variability and comparisons with the GSWM, J. Geophys. Res., 103, 8667-8683, 1998.

Walterscheid, R. J., J. G. de Vore, and S. V. Venkateswaran, Influence of mean zonal motion and meridional temperature gradients on the solar semidiurnal tide: A revised spectral study with improved heating rates, J. Atmos. Sci., 37, 455-470, 1980.

M. E. Hagan (e-mail: hagan@ucar.edu), M. D. Burrage, J. M. Forbes, J. Hackney, W. J. Randel, and X. Zhang 